\title{
Nitrogen self-diffusion in magnetron sputtered Si-C-N films
}

\author{
E. Hüger, ${ }^{1}$ H. Schmidt, ${ }^{1, a)}$ T. Geue,${ }^{2}$ J. Stahn, ${ }^{2}$ U. Tietze,${ }^{3}$ D. Lott,${ }^{3}$ A. Markwitz, ${ }^{4}$ \\ U. Geckle, ${ }^{5}$ and M. Bruns ${ }^{5}$ \\ ${ }^{1}$ Institute of Metallurgy, Materials Physics Group, Clausthal University of Technology, \\ Robert-Koch-Str. 42, D-38678 Clausthal-Zellerfeld, Germany \\ ${ }^{2}$ Laboratory for Neutron Scattering, Paul Scherrer Institut, CH-5232 Villigen PSI, Switzerland \\ ${ }^{3}$ Helmholtz-Zentrum Geesthacht, Max Planck Str. 1, D-21502 Geesthacht, Germany \\ ${ }^{4}$ National Isotope Centre, GNS Science, 30 Gracefield Road, PO Box 31-312 Lower Hutt, New Zealand \\ ${ }^{5}$ Institute for Materials Research III, Karlsruhe Institute of Technology, Hermann-von-Helmholtz-Platz 1, \\ D-76344 Eggenstein-Leopoldshafen, Germany
}

(Received 16 November 2010; accepted 2 April 2011; published online 13 May 2011)

\begin{abstract}
Self-diffusion was studied in magnetron sputtered nitrogen-rich amorphous compounds of the system Si-C-N by using nitrogen as a model tracer. As shown by infra-red spectroscopy a transient metastable region exists, where the structure of the material can be visualized as silicon nitride tetrahedra which are connected by carbo-diimide $(-\mathrm{N}=\mathrm{C}=\mathrm{N}-)$ bonds to a three dimensional amorphous network. In this region diffusion studies are carried out by neutron reflectometry and isotope multilayers as a function of annealing time, temperature and chemical composition. Low diffusivities between $10^{-20}$ and $10^{-24} \mathrm{~m}^{2} / \mathrm{s}$ were found. In the metastable region, diffusion is faster than diffusion in amorphous silicon nitride by 1 to 2 orders of magnitude, while the activation enthalpies of diffusion between 3.1 and $3.4 \mathrm{eV}$ are the same within error limits. This can be explained by the fact that the diffusion mechanism along $\mathrm{SiN}_{4}$ tetrahedra is identical to that in amorphous silicon nitride, however, the carbo-diimide bonds seem to widen the structure, allowing faster diffusion. A correlation between diffusivities and the number of carbo-diimid bonds present in the material is found, where the highest diffusivities are observed for materials with the highest number of carbo-diimid bonds, close to the composition $\mathrm{Si}_{2} \mathrm{CN}_{4}$. (C) 2011 American Institute of Physics. [doi:10.1063/1.3585780]
\end{abstract}

\section{INTRODUCTION}

Silicon carbonitrides (Si-C-N) are advanced multifunctional materials ${ }^{1-5}$ with a wide range of applications. They can be used as structure ceramics, ${ }^{6}$ as wear-protection and corrosion-resistant hard coatings, ${ }^{7}$ for oxidation protection, ${ }^{8}$ as micro-electromechnical parts (MEMS), ${ }^{9}$ as wide bandgap blue-ultraviolet opto-electronic devices, ${ }^{10}$ as tunable electrical conductors, ${ }^{11}$ as sensors, ${ }^{10}$ as novel magnetic materials, ${ }^{12}$ as biomedical implants, ${ }^{13}$ for fuel reforming, ${ }^{14}$ and as negative electrodes in $\mathrm{Li}$ ion batteries. ${ }^{15} \mathrm{Si}-\mathrm{C}-\mathrm{N}$ materials can be produced by a variety of methods like polymer pyrolysis, ${ }^{1,2}$ laser deposition, ${ }^{16}$ ion-implantation, ${ }^{17}$ and magnetron sputtering ${ }^{18,19}$ in form of bulk materials and thin films. After synthesis Si-C-N materials are generally in a complex amorphous state, showing interesting features like nanometer scale phase separation, ${ }^{20}$ transitions to new ternary crystalline compounds ${ }^{2,21,46}$ or also metastable structures. ${ }^{22}$

Quantitative information on the atomic transport properties of these materials is of great importance not only for an understanding of the high temperature stability of the amorphous state, of high temperature creep behavior, and of temperature induced changes of the micro- and nano-structure, but also in order to choose processing parameters to tailor nano-composites with improved mechanical and oxygen resistance properties. ${ }^{23}$ Therefore, it is necessary to investigate

\footnotetext{
a) Author to whom correspondence should be addressed. Electronic mail: harald.schmidt@tu-clausthal.de.
}

the diffusion properties of amorphous Si-C-N by measuring the tracer diffusivities of the constituent elements. Up to now, self-diffusion experiments in amorphous Si-C-N are relatively limited. Self-diffusion of nitrogen, silicon, boron, and carbon was measured in our laboratory for polymerderived amorphous $\mathrm{Si}_{26} \mathrm{~B}_{41} \mathrm{C}_{33}$ and $\mathrm{Si}_{3} \mathrm{BC}_{4.3} \mathrm{~N}_{2}$ ceramics, using ion-implanted stable isotopes and secondary ion mass spectrometry (SIMS). ${ }^{24-27}$ Other groups determined silicon and carbon diffusion with short living radioactive tracers. ${ }^{28}$ The main result was that the diffusivities of all constituents are in the same order of magnitude ${ }^{27}$ and that they obey Arrhenius behavior with relatively high activation enthalpies of diffusion between 5 and $7 \mathrm{eV}$. Impurity diffusion of $\mathrm{Ge}$ and $\mathrm{Au}$ in such type of materials done by the radio tracer method $^{29,30}$ as well as of hydrogen done by SIMS were also reported. ${ }^{31,32}$ Apart from a preliminary study, ${ }^{22}$ up to now no systematic diffusion data exist for thin films of Si-C-N prepared by magnetron sputtering or other methods. The main problem concerning diffusion studies in Si-C-N is that it is extremely difficult to perform successful experiments with conventional methods in such materials. In covalently bound solids, self-diffusivities are very low due to the high binding energy of the components in the order of 3-4 eV. Consequently, applying tracer methods (radioactive or stable) and classical sectioning methods, the material under investigation has to be annealed at relatively high temperatures in order to activate the diffusion process. However, at high temperatures the material starts to crystallize or shows dissociation before any measurable diffusion occurs. The solution to 
TABLE I. Overview on the different types of magnetron sputtered samples, investigated in this study. Given are the chemical composition as determined by RBS, the ratio of the integrated FTIR intensities of the $-\mathrm{N}=\mathrm{C}=\mathrm{N}$ - and the $\mathrm{SiN}_{4}$ peaks, $\mathrm{R}=\mathrm{I}_{\mathrm{N}=\mathrm{C}=\mathrm{N}} / \mathrm{I}_{\mathrm{Si3N} 4}$, the activation enthalpy of diffusion, $\Delta H$, and, the pre-exponential factor $\mathrm{D}_{0}$.

\begin{tabular}{lcccc}
\hline \hline Sample number & Composition $\mathrm{Si}_{\mathrm{x}} \mathrm{C}_{\mathrm{y}} \mathrm{N}_{\mathrm{z}}($ at. \%) & $\mathrm{R}$ & $\Delta H(\mathrm{eV})$ & $\log \left(\mathrm{D}_{0} / \mathrm{m}^{2} \mathrm{~s}^{-1}\right)$ \\
\hline s0 (see Ref. [34]) & $\mathrm{Si}_{3} \mathrm{~N}_{4}$ & - & $3.4 \pm 0.2$ & $-9.7 \pm 0.8$ \\
s1 & $\mathrm{Si}_{33} \mathrm{C}_{14} \mathrm{~N}_{53}$ & $0.17 \pm 0.02$ & $3.3 \pm 0.2$ & $-8.9 \pm 0.6$ \\
s2 (high T) & $\mathrm{Si}_{30} \mathrm{C}_{17} \mathrm{~N}_{53}$ & $0.32 \pm 0.03$ & $3.1 \pm 0.3$ & $-8.3 \pm 0.6$ \\
s2 (low T) & $\mathrm{Si}_{30} \mathrm{C}_{17} \mathrm{~N}_{53}$ & $0.32 \pm 0.03$ & $1.5 \pm 0.1$ & $-15.9 \pm 0.5$ \\
s3 & $\mathrm{Si}_{29} \mathrm{C}_{18} \mathrm{~N}_{53}$ & $0.18 \pm 0.02$ & $3.1 \pm 0.2$ & $-9.3 \pm 0.5$ \\
\hline \hline
\end{tabular}

this problem is to measure considerable low diffusion length. $^{22,33}$ In classical experiments diffusion lengths down to some tens of nanometer can be measured. However, such diffusion lengths are often still too large for covalent amorphous materials in order to avoid crystallization. As recently demonstrated, the method of neutron reflectometry (NR) in combination with isotope multilayers is able to determine even subnanometer diffusion lengths and considerable low diffusivities in inorganic materials. ${ }^{33,34,37,47-52}$ Here, we use this method to determine low diffusivities at low temperatures in amorphous $\mathrm{Si}_{\mathrm{x}} \mathrm{C}_{\mathrm{y}} \mathrm{N}_{\mathrm{z}}$ compounds before crystallization occurs and compare the results for materials with different C:Si ratio.

\section{EXPERIMENTAL SETUP}

For the diffusion experiments high purity $\mathrm{Si}_{\mathrm{x}} \mathrm{C}_{\mathrm{y}}{ }^{14} \mathrm{~N}_{\mathrm{z}} / \mathrm{Si}_{\mathrm{x}}$ $\mathrm{C}_{\mathrm{y}}{ }^{15} \mathrm{~N}_{\mathrm{z}}$ isotope multilayers were deposited by reactive $\mathrm{r}$. $\mathrm{f}$. magnetron co-sputtering. The central bi-layer unit, $\mathrm{Si}_{\mathrm{x}-}$ $\mathrm{C}_{\mathrm{y}}{ }^{14} \mathrm{~N}_{\mathrm{z}} / \mathrm{Si}_{\mathrm{x}} \mathrm{C}_{\mathrm{y}}{ }^{15} \mathrm{~N}_{\mathrm{z}}$, with a thickness of 28-32 nm (depending on the type of sample) was repeated 10 times during sputtering, giving an overall film thickness of about $300 \mathrm{~nm}$. A mixture of argon and nitrogen gas, either nitrogen with natural isotope abundance $\left({ }^{14} \mathrm{~N}\right.$ concentration: $\left.99.63 \%\right)$ or isotopically enriched nitrogen $\left({ }^{15} \mathrm{~N}\right.$ concentration: $\left.99.5 \%\right)$ was used in combination with a silicon target, where six carbon stripes are mounted. The ratio of the areas covered by silicon and carbon was about five. The total concentration of nitrogen in the sputter gas was varied between 20 and 40\%, resulting in different compositions of the deposited film. As substrates, silicon wafers of dimension $10 \times 10 \times 1 \mathrm{~mm}^{3}$ were used. Sputter deposition was carried out with a planar magnetron source (AP\&T, Nürtingen, Germany). Deposition rates of 2$5 \mathrm{~nm} / \mathrm{min}$ were achieved, using an operating pressure of $5 \times 10^{-3}$ mbar and a sputtering power of $160 \mathrm{~W}$ at room temperature. Details of the deposition procedure can be found in Ref. 35 .

The chemical composition of the as-deposited film was determined by Rutherford backscattering spectrometry using a $2.0 \mathrm{MeV}{ }^{4} \mathrm{He}^{+}$ion beam focused to $0.5 \mathrm{~mm}$ in diameter. Considering the backscattering angle of $165^{\circ}$, the $1 \mathrm{~mm}$ aperture mounted at the surface barrier detector, the beam current of $10 \mathrm{nA}$, the charge of $50 \mathrm{C}$, and the accuracy in the stopping cross section values, the accuracy of the measurements is calculated to $5 \%$. The $\mathrm{O}$ impurity concentration was determined by the same method to be less than 1 at. \%. An overview on the samples produced is shown in Table I and Fig. 1. Three different types of $\mathrm{Si}_{\mathrm{x}} \mathrm{C}_{\mathrm{y}} \mathrm{N}_{\mathrm{z}}$ samples termed $\mathrm{s} 1$, s2, and s3 were successfully sputtered. The samples have the same nitrogen concentration, but a varying carbon and silicon concentration. Starting from silcon nitride $\left(\mathrm{Si}_{3} \mathrm{~N}_{4}\right)$, the silicon is (nominally) successively substituted by carbon. The Si:C ratio varies from 1.6 to 2.3. Diffusion annealing was carried out in nitrogen atmosphere at ambient pressure by placing two samples with the surfaces on each other in a silicon nitride powder pack.

In order to recognize particular $\mathrm{C}-\mathrm{N}, \mathrm{Si}-\mathrm{N}$ and $\mathrm{Si}-\mathrm{C}$ functional groups and to follow their annealing time dependence we applied Fourier-transform infra-red spectroscopy (FTIR) in the reflectance mode. FTIR was carried out with an evacuated ( $\mathrm{p}<1$ mbar) Bruker IFS 66v/s spectrometer, which was equipped with a Globar infrared source and a DLTAGS detector. FTIR spectra of Si-C-N films were recorded with $2 \mathrm{~cm}^{-1}$ resolution in reflection geometry and corrected for the substrate contribution, accordingly.

Investigations with X-ray diffractometry (XRD) and $\mathrm{X}$-ray reflectometry (XRR) were carried out using a Bruker D5000 diffractometer (CoK-alpha radiation, $40 \mathrm{kV}, 40 \mathrm{~mA}$ ). For XRD a grazing incidence setup was applied, using an incident angle of $4^{\circ}$.

Neutron reflectometry was done at two different facilities. At the Swiss spallation neutron source (SINQ) the timeof-flight reflectometer AMOR was used at incoming neutron

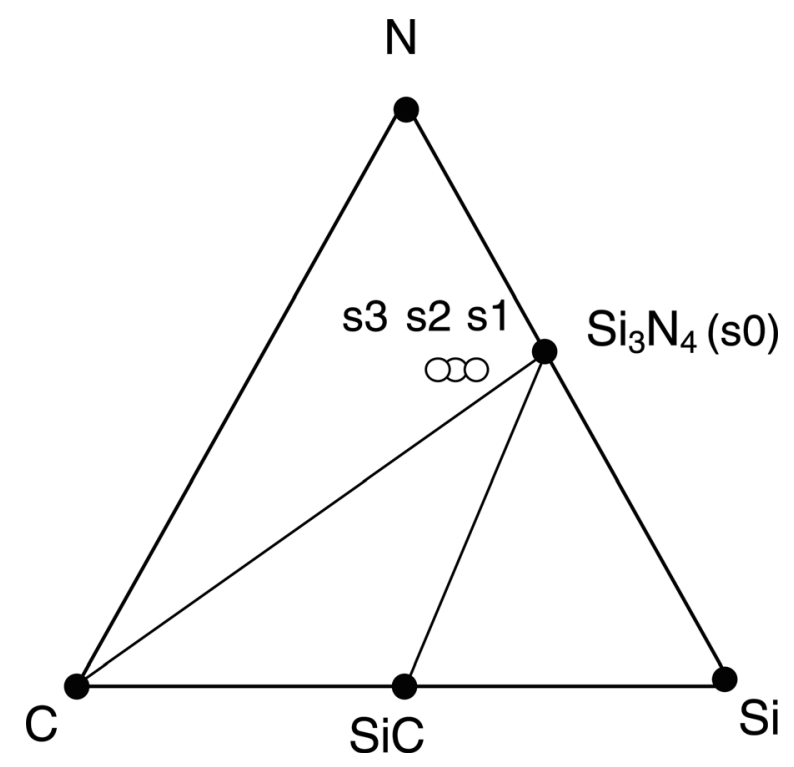

FIG. 1. Isothermal section of the Si-C-N system illustrating the chemical composition of the samples used in the present study: (s1) $\mathrm{Si}_{33} \mathrm{C}_{14} \mathrm{~N}_{53}$, (s2) $\mathrm{Si}_{30} \mathrm{C}_{17} \mathrm{~N}_{53}$, and (s3) $\mathrm{Si}_{29} \mathrm{C}_{18} \mathrm{~N}_{53}$. 
wavelengths between 0.2 and $0.9 \mathrm{~nm}$. Reflectivity patterns were measured at incident angles between $0.3^{\circ}$ and $1.8^{\circ}$, respectively. Further measurements were carried out at the Geesthacht Neutron Facility (GeNF) located at the GKSS research center in Geesthacht (Germany). The reflectometer was operated in angle dispersive $(\theta / 2 \theta)$ mode using a monochromatic neutron beam at a wavelength of $0.635 \mathrm{~nm}$.

\section{RESULTS AND DISCUSSION}

\section{A. Infra-red spectroscopy and X-ray diffractometry}

As shown in Fig. 2, the FTIR reflectance spectra of all three types of as-deposited amorphous Si-C-N films exhibit three vibrational bands. The band visible between 800 and $1000 \mathrm{~cm}^{-1}$ is attributed to $\mathrm{Si}-\mathrm{N}$ bonds including $\mathrm{SiN}_{4}$ tetrahedral vibrations at $940 \mathrm{~cm}^{-1}$ (Refs. 35 and 36) The same vibrations where also observed by us for amorphous silicon nitride films. The wave number of the strong band centered at $2240 \mathrm{~cm}^{-1}$ is indicative for the asymmetric stretching carbo-diimide $(-\mathrm{N}=\mathrm{C}=\mathrm{N}-)$ vibrations $\mathrm{s}^{39}$ or alternatively to cyanamide $(\mathrm{N}-\mathrm{C} \equiv \mathrm{Nl})$ vibrations. ${ }^{17,35,39}$ As pointed out in Ref. 22 the first possibility is more likely in the present case. The weak band between 1400 and $2000 \mathrm{~cm}^{-1}$ can arise from $\mathrm{C} \equiv \mathrm{N}, \mathrm{C}=\mathrm{N}, \mathrm{C}-\mathrm{N}$ or even of $\mathrm{C}=\mathrm{C}$ bonds due to the presence of nitrogen. ${ }^{35,38}$ All bands are broad due to the amorphous structure. A structure model for the Si-C-N film might be that $\mathrm{Si}_{3} \mathrm{~N}_{4}$ tetrahedra are joined by linear $-\mathrm{N}=\mathrm{C}=\mathrm{N}$ - bonds, building-up a three-dimensional amorphous nitride network. There are two different nitride configurations, one with a tetragonal environment $\left(\mathrm{Si}_{3} \mathrm{~N}_{4}\right)$, the other with an almost linear atomic arrangement $(-\mathrm{N}=\mathrm{C}=\mathrm{N}-)$. For a better comparison we normalized the spectra to equal integrated intensity of the $\mathrm{Si}_{3} \mathrm{~N}_{4}$ peak. Taking into account the error limit which is attributed to each FTIR spectrum (see Fig. 2), it can be stated that the $-\mathrm{N}=\mathrm{C}=\mathrm{N}$ - peaks of sample s1 and $\mathrm{s} 3$ are identical, while that of sample $\mathrm{s} 2$ is significantly higher.

The modification of the integrated intensity of the FTIR peak located at $2240 \mathrm{~cm}^{-1}$ during annealing at elevated temperatures is exemplarily shown in Fig. 3 for 700 and 1050 ${ }^{\circ} \mathrm{C}$, respectively. At $700^{\circ} \mathrm{C}$, the FTIR intensity increases fast to a maximum value after $1.6 \mathrm{~h}$ of annealing and maintains

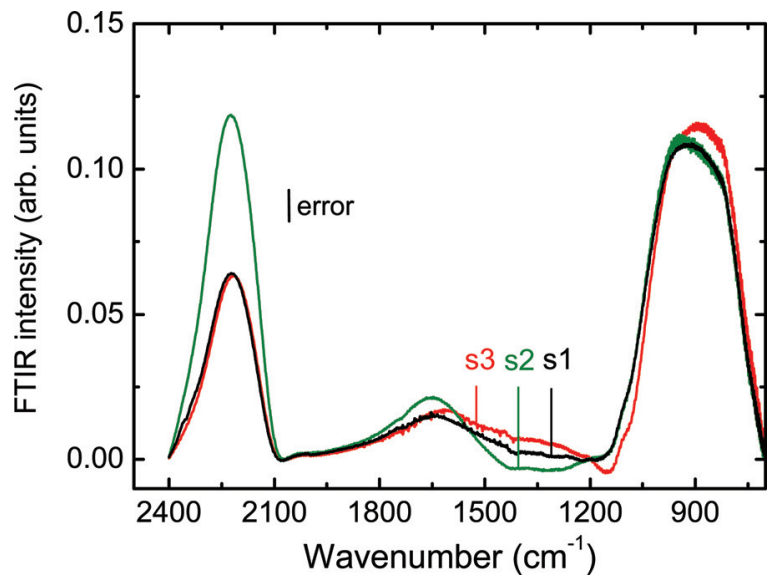

FIG. 2. (Color) FTIR spectra of the as-deposited Si-C-N samples given in Fig. 1.
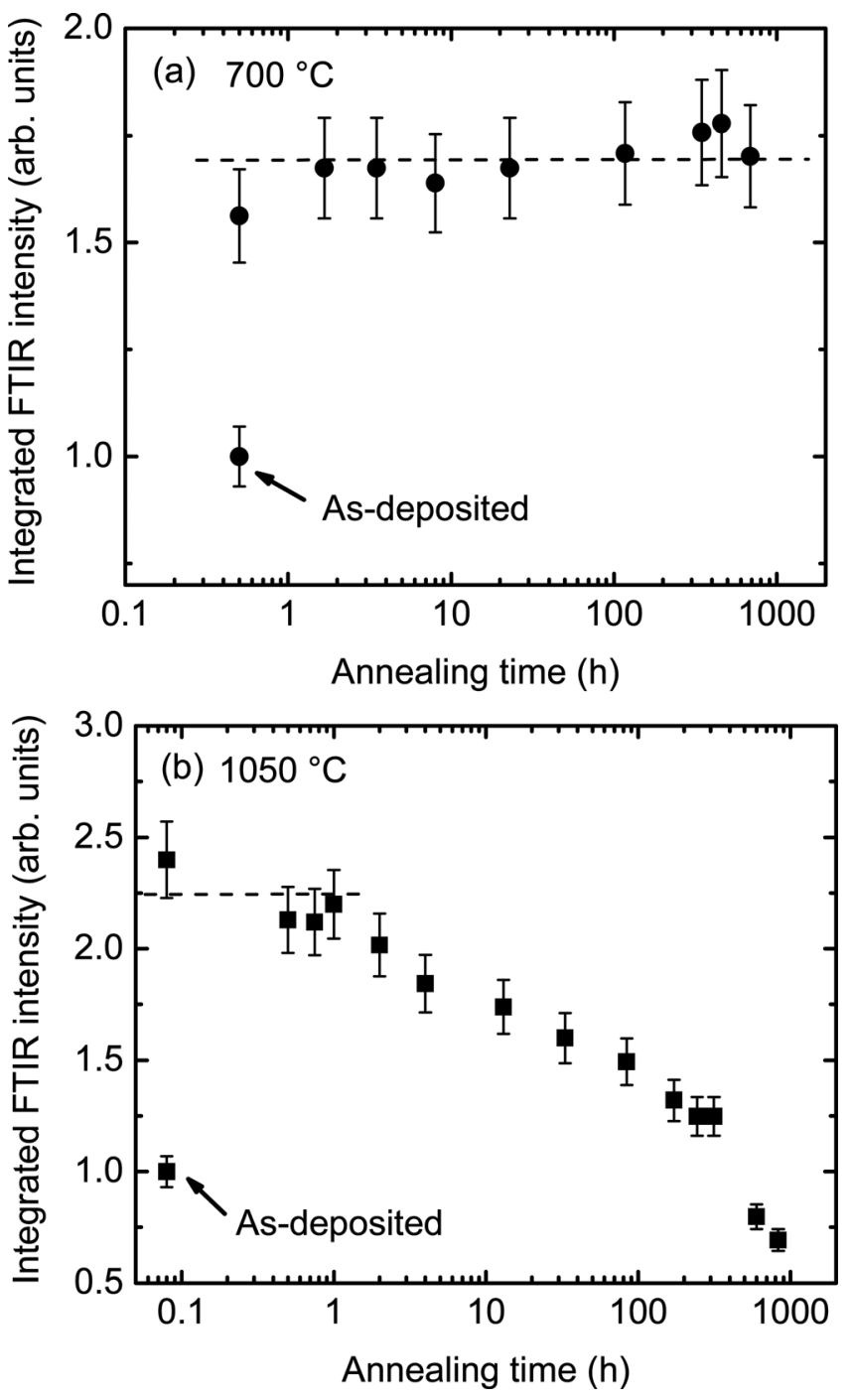

FIG. 3. Integrated FTIR intensity of the band around $2240 \mathrm{~cm}^{-1}$ $(-\mathrm{N}=\mathrm{C}=\mathrm{N}-)$ as a function of annealing time for $\mathrm{Si}_{30} \mathrm{C}_{17} \mathrm{~N}_{53}$ (s2) at (a) $700{ }^{\circ} \mathrm{C}$ and (b) $1050{ }^{\circ} \mathrm{C}$, respectively.

constant at a saturated level for up to $1000 \mathrm{~h}$ of annealing. The initial increase of FTIR intensity can be assigned to the formation of a metastable structure distinguished by $-\mathrm{N}=\mathrm{C}=\mathrm{N}$ - bonds. ${ }^{22}$ The formation process is accompanied by a strong structural re-arrangement of the amorphous network, as confirmed by recent 3D molecular dynamics calculations, ${ }^{45}$ which show a quick significant structural re-organization of Si-C-N during initial annealing. The constant FTIR intensity range can be assigned to an amorphous Si-C-N network with an apparent constant bonding and/or structural configuration. However, as annealing experiments at higher temperatures disclose, this configuration is only transient metastable and dissociates for long annealing times. At $1050{ }^{\circ} \mathrm{C}$ only a small constant region is present for about one hour. As illustrated in Ref. 22 the plateau region can be related to a transient metastable structure, which can be visualized as silicon nitride tetrahedra which are connected by $-\mathrm{N}=\mathrm{C}=\mathrm{N}$ - bonds to a three dimensional amorphous network. For long annealing times this metastable structure dissociates, the number $\mathrm{N}=\mathrm{C}=\mathrm{N}$ bonds is reduced and the material is presumably dissociating to amorphous silicon 


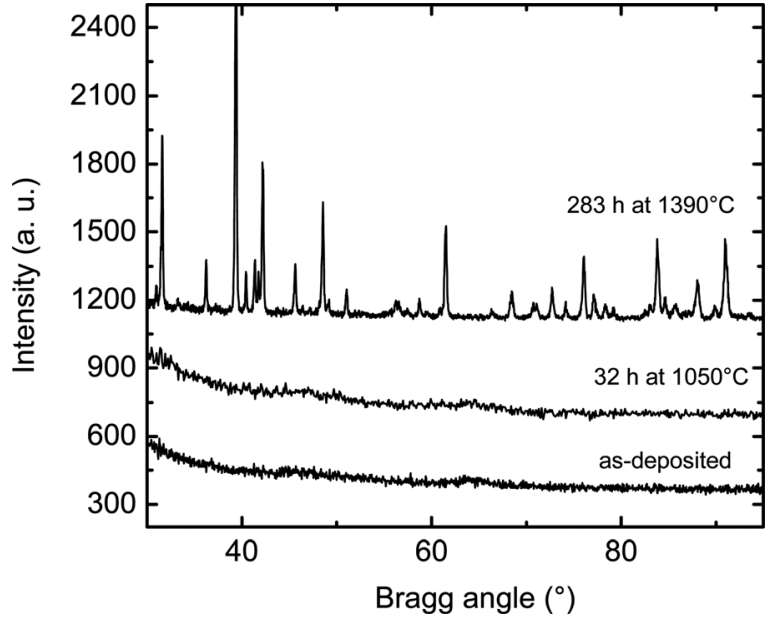

FIG. 4. XRD pattern of sample $\mathrm{Si}_{30} \mathrm{C}_{17} \mathrm{~N}_{53}$ (s2) in the as-deposited state and after annealing at $1050{ }^{\circ} \mathrm{C}$ for $32 \mathrm{~h}$, and at $1390{ }^{\circ} \mathrm{C}$ for $283 \mathrm{~h}$.

nitride, a residual carbon phase and nitrogen gas. ${ }^{22}$ All three types of samples under investigation in this study show the carbo-diimide vibration at $2240 \mathrm{~cm}^{-1}$, however, with a varying intensity (see Fig. 2). Since the integrated FTIR intensity of this band is assumed to be proportional to the number of carbo-diimide bonds present in the sample, the relative amount of carbo-diimide bonds can be assessed (see Table I). It is maximum for the sample series s2.

The results of the XRD investigations are plotted in Fig. 4, exemplarily for the sample s2 in the as-deposited state and for the same sample annealed for $32 \mathrm{~h}$ at $1050{ }^{\circ} \mathrm{C}$. Both curves did not show any Bragg peak, only some broad features are visible, reminiscent of the amorphous structure. All samples used for the diffusion studies show similar patterns, confirming that the amorphous character of the sample found by FTIR is maintained during diffusion annealing. For comparison, the XRD pattern of a sample annealed at $1390{ }^{\circ} \mathrm{C}$ for 283 $\mathrm{h}$ is also shown. At this temperature, complete crystallization of the film and the formation of $\alpha-\mathrm{Si}_{3} \mathrm{~N}_{4}$ and $\beta-\mathrm{Si}_{3} \mathrm{~N}_{4}$ takes place. Such samples were not used in the diffusion study.

\section{B. Diffusion measurements}

As demonstrated in Ref. 22 neutron reflectometry is able to determine diffusivities in the transient metastable structure distinguished by carbo-diimide bonds. This bonding configuration is characteristic for $\mathrm{Si}-\mathrm{C}-\mathrm{N}$ compounds in the nitrogen-rich region. In Fig. 5(a) the neutron reflectivity patterns of all three types of samples under investigation (s1-s3) are shown for the as-deposited state. Also given are simulations based on the program Parratt $32,{ }^{53}$ which is commonly used to describe reflectivity patterns. Bragg peaks of first and third order occur at scattering wave vectors around $0.025 \AA^{-1}$ and $0.06 \AA^{-1}$ due to the ${ }^{14} \mathrm{~N} /{ }^{15} \mathrm{~N}$ isotope modulation and the resulting periodic variation in the neutron scattering length. Small differences in the location of the Bragg peaks for different types of samples result from differences in the bi-layer thickness of the $\mathrm{Si}_{\mathrm{x}} \mathrm{C}_{\mathrm{y}}{ }^{14} \mathrm{~N}_{\mathrm{z}} / \mathrm{Si}_{\mathrm{x}} \mathrm{C}_{\mathrm{y}}{ }^{15} \mathrm{~N}_{\mathrm{z}}$ unit, determined by fitting to $27 \mathrm{~nm}$ (s3), $30 \mathrm{~nm}$ (s2), and $33 \mathrm{~nm}$ (s3).

The small shoulder which is visible exclusively in the reflectogram of sample s1 at $0.019 \AA^{-1}$ can be reproduced
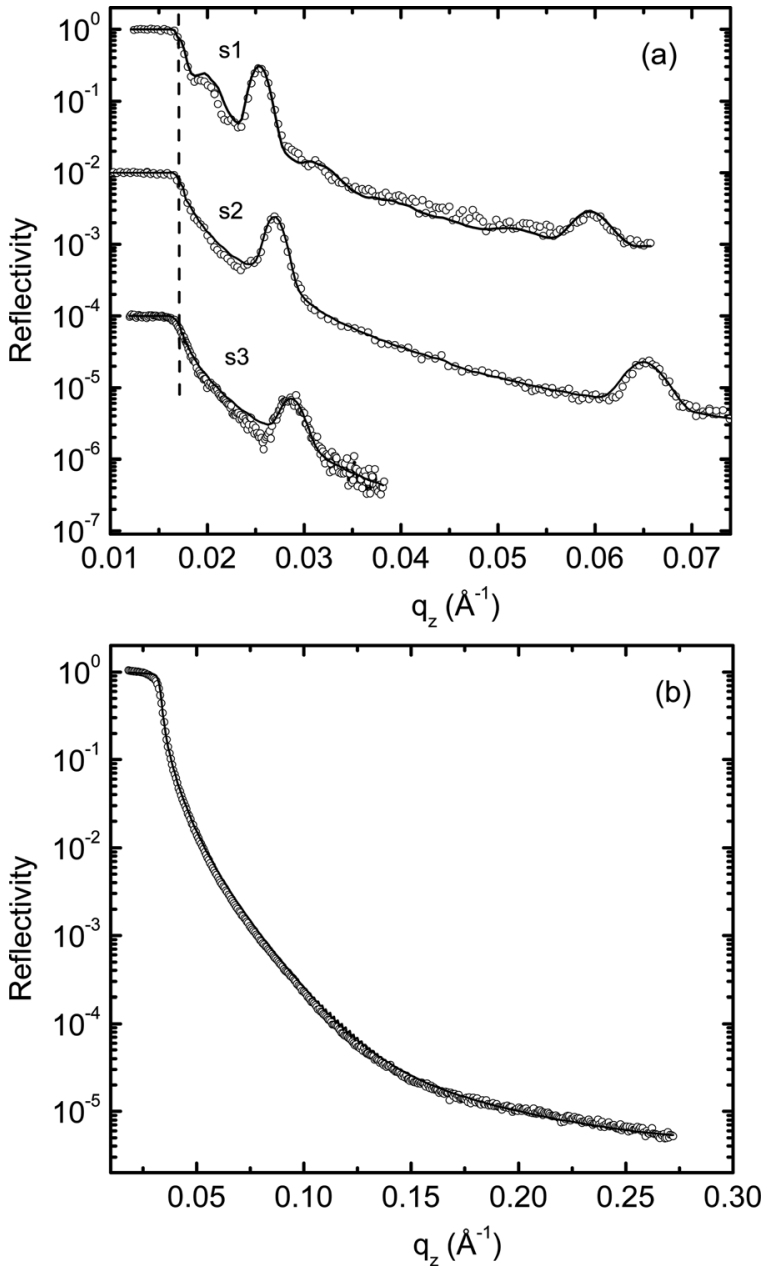

FIG. 5. (a) Neutron reflectivity pattern of the samples $\mathrm{Si}_{33} \mathrm{C}_{14} \mathrm{~N}_{53}$ (s1), $\mathrm{Si}_{30} \mathrm{C}_{17} \mathrm{~N}_{53}$ (s2) and $\mathrm{Si}_{29} \mathrm{C}_{18} \mathrm{~N}_{53}$ (s3) in the as-deposited state. The patterns of s2 and s3 are shifted for clarity. (b) X-ray reflectivity pattern of the sample s1 in the as-deposited state for comparison. The lines correspond to simulations done by the program Parratt32 using a reflectometer resolution of $\Delta q_{z} / q_{z}=5 \%$. The background is adjusted accordingly in order to optimize the fit. For further details see text.

very well by the Parratt32 simulation, assuming a distortion of the perfect periodicity in the bi-layer arrangement. Due to a dysfunction in sputtering, $\mathrm{Si}_{33} \mathrm{C}_{14}{ }^{14} \mathrm{~N}_{53}$ was deposited instead of $\mathrm{Si}_{33} \mathrm{C}_{14}{ }^{15} \mathrm{~N}_{53}$ during a single deposition cycle. Investigations by Secondary Ion Mass Spectrometry (not shown) confirmed the existence of such a distortion. The reflectivity edge is located at about $0.017 \AA^{-1}$ (dashed line in Fig. 5(a)) and differs by about $\pm 0.003 \AA^{-1}$ for the three samples. This is within the error limit given by the statistically reproducibility of different measurements done on the same sample. Small deviations during sample alignment at the reflectometer may result in such small variations. For the three samples no systematic variation of the reflectivity edge is found. This means that the mass density of about $(2.7 \pm 0.1) \mathrm{g} / \mathrm{cm}^{3}$ is not significantly different for the three samples. The density was calculated from the location of the reflectivity edge by using the simulation program Parratt32. ${ }^{53}$

In Fig. 5(b) an X-ray reflectometry measurement in combination with a Parratt32 fit of sample s1 in the as-deposited state is plotted. In contrast to the neutron reflectivity, no 

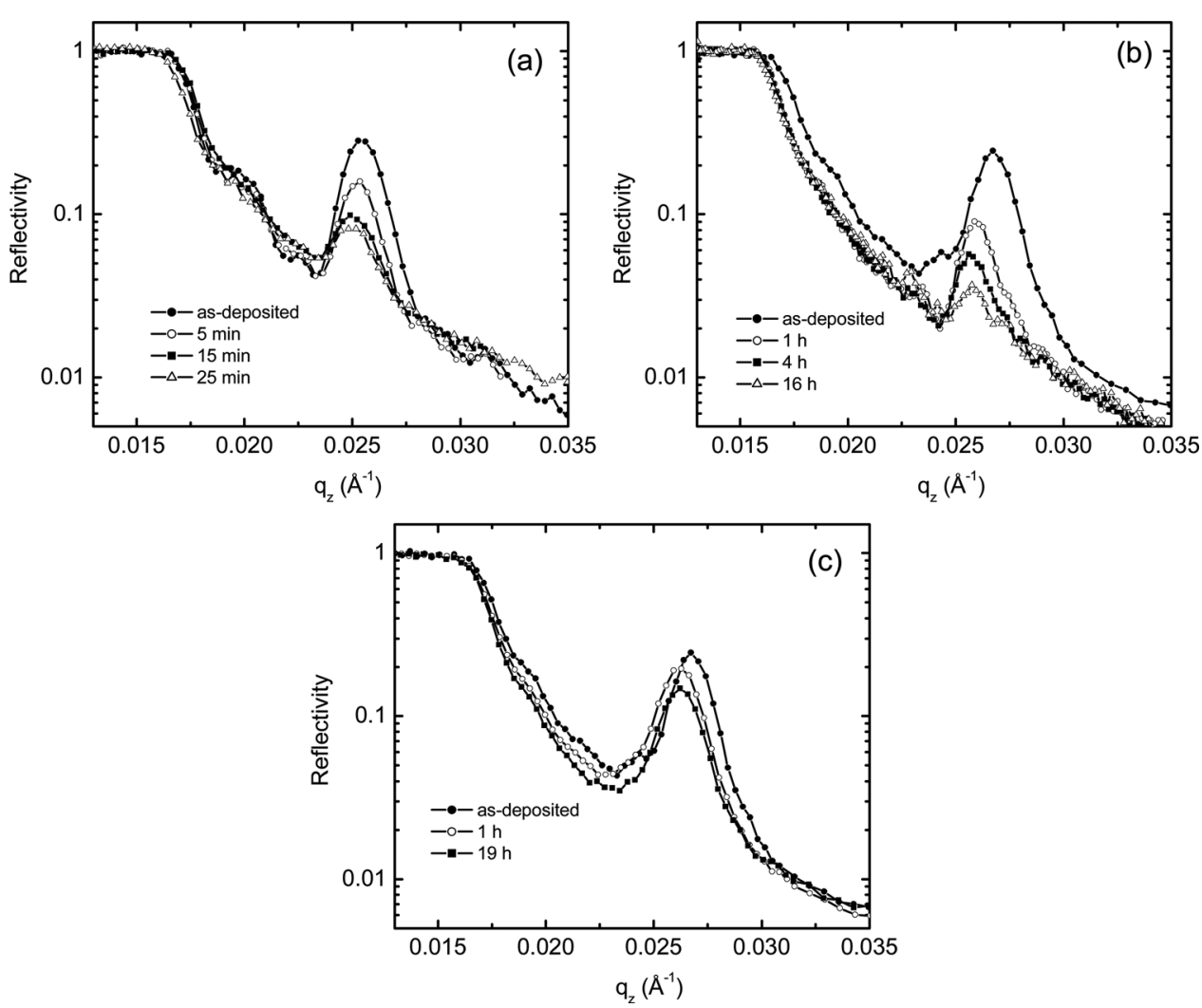

FIG. 6. Neutron reflectivity patterns of isotope multilayers in the as-deposited state and after annealing for various times for (a) $\mathrm{Si}_{33} \mathrm{C}_{14} \mathrm{~N}_{53}$ (s1) at $1250{ }^{\circ} \mathrm{C}$, (b) $\mathrm{Si}_{30} \mathrm{C}_{17} \mathrm{~N}_{53}$ (s2) at $1050{ }^{\circ} \mathrm{C}$, and (c) $\mathrm{Si}_{30} \mathrm{C}_{17} \mathrm{~N}_{53}$ (s2) at $900{ }^{\circ} \mathrm{C}$.
Bragg peaks are visible, only the background resulting from Fresnel reflectivity. Since X-ray reflectometry probes the contrast in the electron system of a material, the experiment shows that there is no chemical or density gradient within the isotope multilayer and pure isotope interdiffusion (i.e., self-diffusion) is measured by neutron reflectometry.

In Fig. 6 three characteristic series of neutron reflectivity patterns are exemplarily shown for samples in the as-deposited state and after diffusion annealing at different temperatures and times. An intensity decrease of the Bragg peak is clearly visible for the annealed samples due to isotope interdiffusion. ${ }^{33}$ It is obvious from Fig. 6 that the Bragg peak does not only decrease in intensity but is also slightly shifted to lower $q_{z}$ values. Such behavior is also observed for other annealing temperatures and sample compositions, however, pronounced to a different degree. Variations in the location of the peak maximum can be explained by a modification of the Si-C-N film thickness during annealing caused by a modification of the mass density if the number of scattering atoms is assumed to be constant. A shift to the left corresponds to a decrease in the mass density as discussed in Ref. 34. As further obvious from Fig. 6, this shift is mainly restricted to the first annealing step and corresponds to a change in mass density of some percent (see also Ref. 22). As already discussed in Ref. 22, this density change is correlated to the formation of the metastable state during annealing. The increase of the FTIR emission from carbo-diimide functional groups is accompanied by a mass density decrease. In contrast, during annealing in the metastable region, the shift of the Bragg peak is no more discernable, implying approximately a constant mass density. Besides a shift of the Bragg peaks to lower $q_{z}$ values, a reduction in mass density should be reflected also in a shift of the critical edge of total reflection to lower $q_{z}$ values. As given in Fig. 6(b), for large mass density changes a shift of the critical angle to lower $q_{z}$ values is indeed observed. However, for smaller mass density changes the shift of the critical edge is hidden in the statistical error, because it is less sensitive to mass changes than the shift of the Bragg peak. As will be shown below, diffusivities will be extracted only in the metastable region, where no significant shift of the Bragg peak occurs. Consequently for the present analysis a correlation of diffusion behavior and Bragg peak shift is not reasonable.

The diffusivities, D, were calculated from the decay of the $n$th order Bragg peak intensity due to isotope intermixing according to ${ }^{22}$

$$
D(t)=-\frac{l^{2}}{8 \pi^{2} n^{2} \Delta t} \ln \left(\frac{I_{i}}{I_{f}}\right)
$$

where $l$ is the bilayer thickness, $I_{f}$ is the intensity of the Bragg peak after the annealing time $t_{f}, I_{i}$ is the intensity of the Bragg peak at the starting time of the diffusion anneal $t_{i}$, and $\Delta t=\left(t_{f}-t_{i}\right)$ is the annealing time between starting and final state, with $t=\left(t_{f}+t_{i}\right) / 2$. As intensity of the "starting state" that of the as-deposited sample $(t=0)$ or that of an already annealed Si-C-N film can be taken. Note that according to Eq. (1) average diffusivities are calculated, which correspond to a state defined between the starting and the final time of the anneal. On the other hand, the presented FTIR results illustrate the current status of the bonding configuration after each annealing step. The local distortion of 
the bi-layer periodicity (shoulder in the reflectogram of sample s1 in Fig. 5(a)) does not disturb the determination of diffusivities from the experimental data. As obvious from Fig. 6(a) the shoulder is also decreasing during annealing in accordance with the Bragg peak, meaning it exclusively results from isotope interdiffusion.

Nitrogen diffusivities as function of annealing time are illustrated exemplarily in Fig. 7 for temperatures of 700 and $1050{ }^{\circ} \mathrm{C}$, respectively. The corresponding annealing time dependence of the FTIR intensity is presented in Fig. 2. Paying attention to the initial region where the metastable structure is formed, we select for the "starting state" of our analysis the first neutron reflectivity pattern that securely can be assigned to the metastable structural state (maximum in FTIR intensity). This corresponds to an annealing time of 8 $\mathrm{h}$ at $700^{\circ} \mathrm{C}$ and $15 \mathrm{~min}$ at $1050^{\circ} \mathrm{C}$, respectively. The diffusivities resemble the annealing time behavior of the bondingconfiguration obtained by FTIR. The diffusivity is constant in the region where the $\mathrm{N}=\mathrm{C}=\mathrm{N}$ peak shows its constant maximum value. However, the diffusivity decreases where the $\mathrm{N}=\mathrm{C}=\mathrm{N}$ peak also decreases. At $700^{\circ} \mathrm{C}$ the diffusivities do not decreases at all in the annealing time domain investigated (Fig. 7(a)), in accordance with the $-\mathrm{N}=\mathrm{C}=\mathrm{N}$ - FTIR peak stability at that temperature. Such a behavior also occurs for temperatures up to $900{ }^{\circ} \mathrm{C}$. For higher temperatures, as illustrated for $1050^{\circ} \mathrm{C}$ (Fig. 7(b)), the first identical
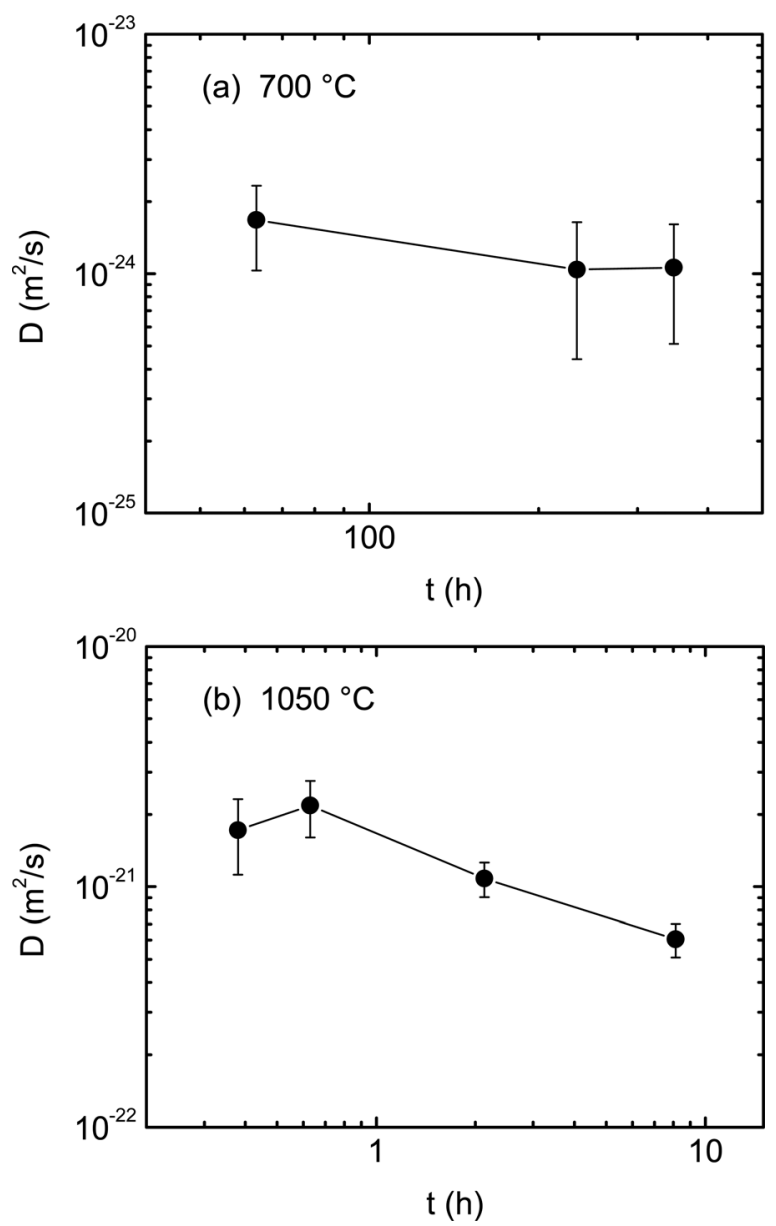

FIG. 7. Self-diffusivities of nitrogen in amorphous $\mathrm{Si}_{30} \mathrm{C}_{17} \mathrm{~N}_{53}$ (s2) films as a function of annealing time at (a) $700{ }^{\circ} \mathrm{C}$ and (b) $1050{ }^{\circ} \mathrm{C}$, respectively. two diffusivities correspond also to a constant maximum intensity of the $\mathrm{N}=\mathrm{C}=\mathrm{N}$ peak. For longer annealing times, diffusivities decrease continuously. In this range the carbodiimide bonds dissociate. For extremely long annealing times it is expected that the diffusivity reaches that of silicon nitride, which is considerably lower (see below). In summary, neutron reflectometry and FTIR revealed the existence of a transient metastable $\mathrm{Si}-\mathrm{C}-\mathrm{N}$ structural state characterized by a constant diffusivity and unchanged $-\mathrm{N}=\mathrm{C}=\mathrm{N}$ vibration strength.

As recently demonstrated for amorphous silicon nitride $^{34}$ a time-dependent decrease of diffusivities might not only be present if atomic movement takes place in a dissociating micro structure and bonding configuration, but also in a stable homogeneous amorphous state. There, the reason for the timely varying diffusivity is structural relaxation of the amorphous network. Structural relaxation is an omnipresent process in amorphous materials ${ }^{40-43}$ leading to irreversible short-range structural rearrangements during annealing at considerable low temperatures. The solid transforms from a less stable to a more stable, but still amorphous state, accompanied by a re-arrangement of bond lengths and bond angles, a reduction of strain and also a redistribution of point defects, ${ }^{40}$ which modifies diffusivities. Point defects responsible for diffusion are annihilated at sinks during annealing. For long annealing times, a range with constant diffusivities is commonly reached, where no more defect annihilation takes place. It is often termed "relaxed amorphous state." At high temperatures structural relaxation may take place on very short time scales, less than some seconds, as demonstrated in Ref. 34.

The results on $\mathrm{Si}-\mathrm{C}-\mathrm{N}$ at $700{ }^{\circ} \mathrm{C}$ (Fig. 7(a)) show no significant time dependence of diffusivities in the metastable structural state. That means that structural relaxation is already completed during the initial period of annealing, where the metastable structure is formed and that the diffusivities correspond to a relaxed state. If temperature is raised the situation may change, because the time constants of both kinetic processes, the formation of the metastable structure and structural relaxation within the metastable structure might have a different temperature dependence. Consequently, we cannot exclude that also during the time period where the metastable structure is stable, structural relaxation and (at least slightly) time dependent diffusivities are present. Consequently, for our further analysis we refer only to data where a constant diffusivity and a constant intensity of the FTIR peak are present.

In Fig. 8 the determined nitrogen diffusivities in metastable $\mathrm{Si}-\mathrm{C}-\mathrm{N}$ are plotted as a function of reciprocal temperature for the three types of samples under investigation. Diffusion coefficients over more than four orders of magnitude were measured. For comparison, the results obtained by NR for amorphous $\mathrm{Si}_{3} \mathrm{~N}_{4}$ in the relaxed state ${ }^{34,44}$ are also presented. The comparison of the results for the different types of samples shows that diffusion in all Si-C-N samples under investigation is faster than in $\mathrm{Si}_{3} \mathrm{~N}_{4}$ by a factor of 10 (sample s1), a factor of 30 (sample s3) and a factor of 200 (sample s2). Least-squares fitting of the diffusivities of each type to the Arrhenius equation 


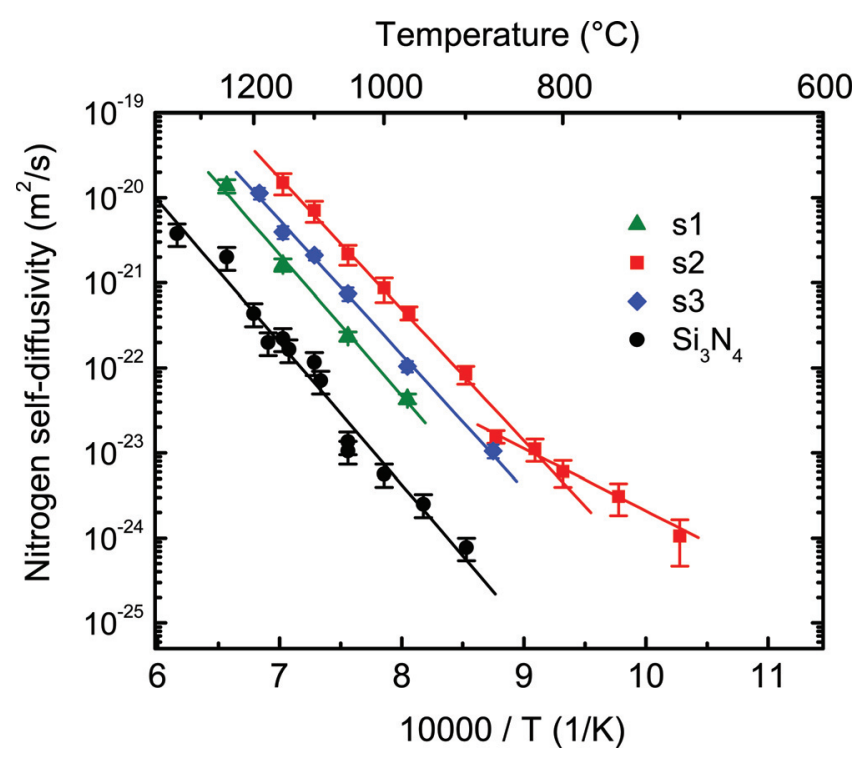

FIG. 8. Nitrogen diffusivities in the metastable region of amorphous Si-C-N films as a function of reciprocal temperature. The diffusivities of amorphous silicon were taken from Ref. 34 .

$$
D=D_{0} \exp \left(-\Delta \mathrm{H} / \mathrm{k}_{B} \mathrm{~T}\right)
$$

results in activation enthalpies, $\Delta H$, and pre-exponential factors, $D_{0}$, as given in Table I. The sample which was investigated in closest detail is sample s2, with the strongest $-\mathrm{N}=\mathrm{C}=\mathrm{N}$ - vibration peak. As obvious from Fig. 8, the whole data set cannot be fitted by a single Arrhenius line. However, linear segments in Arrhenius plots indicate that the diffusion process is governed by a single activation enthalpy within that region. A linear fit through the diffusion coefficients measured between 800 and $1150{ }^{\circ} \mathrm{C}$ and between 700 and $870{ }^{\circ} \mathrm{C}$ is depicted. For the high temperature range the activation enthalpy is determined to be $H=(3.1 \pm 0.2) \mathrm{eV}$, which is identical to that obtained of $\mathrm{Si}_{3} \mathrm{~N}_{4}(H=(3.4 \pm 0.3)$ $\mathrm{eV})$. For the low temperature range we obtain an activation enthalpy of only $H=(1.5 \pm 0.1) \mathrm{eV}$.

Comparison of the high temperature region reveals that all three Si-C-N samples show within error limits the same activation enthalpy and the same pre-exponential factor (see Table I). Further, these two quantities are also identical to that of amorphous $\mathrm{Si}_{3} \mathrm{~N}_{4}$ within error limits. This indicates that the same basic diffusion mechanism is present for all types of samples in that region. However, it is not possible to determine which of the two parameters (activation enthalpy or pre-exponential factor) is responsible for the increase of diffusivity. Qualitatively, the increase can be explained in the following way. As stated in Refs. 34 and 44, diffusion in relaxed amorphous silcon nitride is governed by a direct diffusion mechanism via structural defects without the mediation of thermal point defects. In that case, the activation enthalpy of diffusion is essentially determined by the defect migration enthalpy $\left(\Delta H_{D}=\Delta H_{m}\right)$. The higher diffusivities in $\mathrm{Si}-\mathrm{C}-\mathrm{N}$ is attributed to be the consequence of the presence of $-\mathrm{N}=\mathrm{C}=\mathrm{N}$ - bonds. These linear bonds might modify the structure in a way that a more open structure is present and diffusion is accelerated. Diffusion is taking place along
" $\mathrm{Si}_{3} \mathrm{~N}_{4}$ domains" formed by the tetrahedra within the amorphous network.

At low temperatures, a different, still unknown, diffusion mechanism or alternatively, a different structural state seems to be present, as indicated by the considerably lower activation enthalpy. A possible explanation for that result might be that at low temperatures the metastable structure is composed of a more disordered amorphous network structure. Further investigations on that point by detailed FTIR and XPS experiments are in progress.

More insight into the diffusion mechanism at high temperatures can be delivered if the results on diffusion are correlated to the results of the FTIR experiments. In Table I the ratio of the integrated FTIR intensities of $-\mathrm{N}=\mathrm{C}=\mathrm{N}$ - bonds and $\mathrm{Si}-\mathrm{N}$ bonds, $\mathrm{R}$, is given for the different samples. This ratio is proportional to the ratio of the relative number of bonds that can be attributed to each configuration. Sample s2 shows the highest value of $\mathrm{R}$ and $\mathrm{s} 1$ and $\mathrm{s} 3$ show reduced values. Obviously, a correlation of $\mathrm{R}$ to the increasing $\mathrm{C}$ content of the sample is not given. However, a correlation of $\mathrm{R}$ to the diffusivities is present. Sample s2 shows also the highest diffusivities, while those of s1 and s3 are lower. These results can now be interpreted in a way that diffusion is increasing with the relative number of $-\mathrm{N}=\mathrm{C}=\mathrm{N}$ - bonds present in the sample. The formation of more and more $-\mathrm{N}=\mathrm{C}=\mathrm{N}$ - bonds "widens" the structure and accelerates diffusion, however, diffusion is still taking place via $\mathrm{SiN}_{4}$ tetrahedra as observed in $\mathrm{Si}_{3} \mathrm{~N}_{4}$. As obvious from Figure 1 the sample with the highest diffusivity and the highest intensity of the $-\mathrm{N}=\mathrm{C}=\mathrm{N}$ - peak is located closest to the composition $\mathrm{Si}_{29} \mathrm{C}_{14} \mathrm{~N}_{57}$ which corresponds to $\mathrm{Si}_{2} \mathrm{CN}_{4}$, a recently found ternary crystalline compound, ${ }^{46}$ where one silicon atom is substituted by one carbon atom. A higher amount of carbon incorporated in the Si-C-N structure is not resulting in the formation of a higher amount of $-\mathrm{N}=\mathrm{C}=\mathrm{N}$ - bonds. The composition $\mathrm{Si}_{2} \mathrm{CN}_{4}$ seems to be some kind of "optimum" arrangement of the two structural units, i.e., $\mathrm{SiN}_{4}$ tetrahedra and $-\mathrm{N}=\mathrm{C}=\mathrm{N}$ - bonds, in a geometric and energetic way.

\section{CONCLUSION}

We carried out nitrogen diffusion studies on metastable amorphous silicon carbonitride $\left(\mathrm{Si}_{\mathrm{x}} \mathrm{C}_{\mathrm{y}} \mathrm{N}_{\mathrm{z}}\right)$ films with an increasing $\mathrm{C}$ :Si ratio as a function of temperature. The structure of these films is different compared to the structure of amorphous silicon nitride in a way that the $\mathrm{SiN}_{4}$ tetrahedra which form the basic structure element are connected by carbo-diimide $(-\mathrm{N}=\mathrm{C}=\mathrm{N}-)$ bonds to a three dimensional amorphous network. The incorporation of $-\mathrm{N}=\mathrm{C}=\mathrm{N}$ - bonds widens the amorphous structure and leads to accelerated diffusion.

\section{ACKNOWLEDGMENTS}

We would like to thank V. Recksiek and N. Li for annealing treatments and W. Daum for the possibility to use his FTIR equipment. This work is based on experiments performed at the Swiss spallation neutron source SINQ, Paul Scherrer Institute, Villigen, Switzerland and the Geesthacht 
neutron facility, GeNF, Germany. This research has been supported by the German Research Foundation under the contract Schm1569/7-1 and by the European Commission under the 7th Framework Programme through the "Research Infrastructures" action of the "Capacities" Programme, Contract No: CP-CSA_INFRA-2008-1.1.1 Number 226507NMI3.

${ }^{1}$ R. Riedel, G. Passing, H. Schönfelder, and R. J. Brook, Nature 355, 714 (1992).

${ }^{2}$ R. Riedel, E. Horvarth-Bordon, P. Kroll, G. Miehe, D. Dzivenko, H.-J. Kleebe, P. A. van Aken, and S. Lauterbach, J. Ceram. Soc. Jpn. 116, 674 (2008).

${ }^{3}$ E. Kroke, Y. L. Li, C. Konetschny, E. Lecomte, C. Fasel, and R. Riedel, Mat. Sci. Eng. R26, 97 (2000).

${ }^{4} \mathrm{M}$. Jansen, B. Jaschke, and T. Jaschke, in High Performance Non-Oxide Ceramics, (Springer, Berlin, 2002) Vol. 101, p. 137.

${ }^{5}$ J. Bill, J. Seitz, G. Thurn, J. Dürr, L. Canel, B. Z. Janos, A. Jalowiecki, D. Sauter, S. Schempp, H.-P. Lamparter, J. Mayer, and F. Aldinger, Phys. Stat. Sol. 166, 269 (1998).

${ }^{6}$ R. Kumar, Y. Cai, P. Gerstel, R. Rixecker, and F. Aldinger, J. Mater. Sci. 41, 7088 (2006).

${ }^{7}$ D. Pech, N. Schupp, P. Steyer, T. Hack, Y. Gachon, C. Heau, A-S. Loir, and J. C. Sanchez-Lopez, Wear 266, 832 (2009).

${ }^{8}$ L. An, R. Riedel, C. Konetschny, H. J. Kleebe, and R. Raj, J. Am. Ceram. Soc. 81, 1349 (1998).

${ }^{9}$ M. Schulz, Adv. Appl. Ceram. 108, 454 (2009).

${ }^{10}$ T.-H. Chou, Y.-K. Fang, Y.-T. Chiang, C.-I. Lin, and C.-Y. Yang, Sens. Actuators A 147, 60 (2008).

${ }^{11}$ A. M. Hermann, Y.-T. Wang, P. A. Ramakrishnan, D. Balzar, L. An, C. Haluschka, and R. Riedel, J. Am. Ceram. Soc. 84, 2260 (2001).

${ }^{12}$ A. Francis and R. Riedel, J. Appl. Phys. 105, 07 A318 (2009).

${ }^{13}$ P. Colombo, Science 322, 381 (2008)

${ }^{14}$ I. K. Sung, M. Mitchel, D. P. Kim, P. J. A. Kenis, Adv. Funct. Mater. 15, 1336 (2005).

${ }^{15}$ Y. Feng, Electrochem. Acta 55, 5860 (2010).

${ }^{16}$ N.-M. Park, S. H. Kim, and G. Y. Sung, J. Appl. Phys. 94, 2725 (2003).

${ }^{17}$ M. Rudolphi, H. Baumann, U. Geckle, and M. Bruns, J. Vac. Sci. Technol. A 26, 1018 (2008).

${ }^{18}$ H. Lutz, M. Bruns, F. Link, and H. Baumann, Thin Solid Films 332, 230 (1998).

${ }^{19}$ J. Vlcek, M. Kormunda, J. Cizek, Z. Soukup, V. Perina, and J. Zemek, Diamond. Rel. Mater. 12, 1287 (2003).

${ }^{20}$ J. Haug, P. Lamparter, M. Weinmann, and F. Aldinger, Chem. Mater. 16, 72 (2004).

${ }^{21}$ J. E. Lowther, M. Amkreutz, Th. Frauenheim, E. Kroke, and R. Riedel, Phys. Rev. B 68, 033201 (2003).

${ }^{22}$ E. Hüger, H. Schmidt, J. Stahn, B. Braunschweig, U. Geckle, and M. Bruns, Phys. Rev. B. 80, R220101 (2009).

${ }^{23}$ H. Schmidt, Soft Mater. 4, 143 (2006).
${ }^{24}$ H. Schmidt, G. Borchardt, S. Weber, S. Scherrer, H. Baumann, A. Müller, and J. Bill, J. Appl. Phys. 88, 1827 (2000).

${ }^{25}$ H. Schmidt, G. Borchardt, H. Baumann, S. Weber, S. Scherrer, A. Müller, and J. Bill, Def. Diff. For. 194-199, 941 (2001).

${ }^{26}$ H. Schmidt, G. Borchardt, S. Weber, H. Scherrer, H. Baumann, A. Müller, and J. Bill, J. Non-Cryst. Solids 298, 232 (2002).

${ }^{27}$ H. Schmidt, G. Borchardt, O. Kaïtasov, and B. Lesage, J. Non-Cryst. Solids. 353, 4801 (2007).

${ }^{28}$ Th. Voss, A. Strohm, and W. Frank, Zeitschr. Metallk. 94, 419 (2003).

${ }^{29}$ S. Matics and W. Frank, J. Non-Crys. Sol. 266-269, 830 (2000).

${ }^{30}$ S. Matics and W. Frank, Diff. Def. Forum. 194-199, 947 (2001).

${ }^{31}$ W. Gruber, G. Borchardt, and H. Schmidt, J. Non-Cryst. Solids. 353, 4121 (2007).

${ }^{32}$ H. Schmidt, G. Borchardt, U. Geckle, M. Bruns, and H. Baumann, J. Phys.: Condens. Matter. 18, 5363 (2006).

${ }^{33}$ H. Schmidt, M. Gupta, J. Stahn, T. Gutberlet, and M. Bruns, Acta Mater. 56, 464 (2008).

${ }^{34}$ H. Schmidt, W. Gruber, T. Gutberlet, J. Stahn, M. Ay, U. Geckle, and M. Bruns, J. Appl. Phys. 102, 043516 (2007).

${ }^{35}$ H. Lutz, Ph.D. thesis, Research Center Karlsruhe, Germany, 2001.

${ }^{36}$ J. P. Luongo, Appl. Spectrosc. 38, 195 (1984).

${ }^{37}$ E. Hüger, U. Tietze, D. Lott, H. Bracht, E. E. Haller, D. Bougeard, and H. Schmidt, Appl. Phys. Lett. 93, 162104 (2008).

${ }^{38}$ A. C. Ferrari, S. E. Rodil, and J. Robertson, Phys. Rev. B 67, 155306 (2003).

${ }^{39}$ R. Riedel, E. Korke, A. Greiner, A. O. Gabriel, L. Ruwisch, J. Nicolich, and P. Kroll, Chem. Mater. 10, 2964 (1998).

${ }^{40}$ C. A. Angell, K. L. Ngai, G. B. McKenna, P. F. McMillan, and S. W. Martin, J. Appl. Phys. 88, 3113 (2000).

${ }^{41}$ U. Buchenau, H. M. Zhou, N. Nucker, K. S. Gilroy, and W. A. Phillips, Phys. Rev. Lett. 60, 1318 (1988).

${ }^{42}$ A. van den Beukel and S. Radelaar, Acta Metall. 31, 419 (1983).

${ }^{43}$ M. Ishimaru, I.-T. Bae, Y. Hirotsu, S. Matsumura, and K. E. Sickafus, Phys. Rev. Lett. 89, 055502 (2002).

${ }^{44}$ H. Schmidt, M. Gupta, and M. Bruns, Phys. Rev. Lett. 96, 055901 (2006).

${ }^{45}$ V. Tomar, M. Gan, and H. S. Kim, J. Europ. Ceram. Soc. 30, 2223 (2010).

${ }^{46}$ R. Riedel, A. Greiner, G. Miehe, W. Dressier, H. Fuess, J. Bill, and J. F. Aldinger, Angew. Chem. Int. Ed. 36, 603 (1997).

${ }^{47}$ J. Speakmann, P. Rose, J. A. Hunt, N. Cowlam, R. E. Somekh, and A. L. Greer, J. Magn. Magn. Mater. 156, 411 (1996).

${ }^{48}$ S. M. Baker, G. S. Smith, N. J. S. Brown, M. Nastasi, and K. Hubbard, Phys. Rev B. 55, 7255 (1996).

${ }^{49}$ M. Gupta, A. Gupta, J. Stahn, M. Horisberger, T. Guberlet, and P. Allenspach, P. Phys. Rev. B 70, 184206 (2004).

${ }^{50}$ M. Gupta, A. Gupta, S. Chakravarty, R. Gupta, and R. T. Guberlet, Phys. Rev. B 74, 104203 (2006).

${ }^{51}$ M. Gupta, A. Gupta, J. Stahn, and T. Gutberlet, New J. Phys. 10, 053031 (2008).

${ }^{52}$ S. Chakravarty, U. Tietze, D. Lott, N. P. Lalla, A. Gupta, and H. Schmidt, Phys. Rev. B 80, 014111 (2009).

${ }^{53}$ C. Braun, Parratt32 or the reflectometry tool, HMI, Berlin, 1997-1999, available at http://www.helmholtz-berlin.de/bensc/download/parratt32. 